\title{
Mental illness in metropolitan, urban and rural Georgia populations
}

William C Reeves ${ }^{1}$, Jin-Mann S Lin ${ }^{1,2^{*}}$ and Urs M Nater ${ }^{3}$

\begin{abstract}
Background: Mental illness represents an important public health problem. Local-level data concerning mental illness in different populations (e.g., socio-demographics and residence - metropolitan/urban/rural) provides the evidence-base for public health authorities to plan, implement and evaluate control programs. This paper describes prevalence and covariates of psychiatric conditions in Georgia populations in three defined geographic areas.

Methods: Data came from the Georgia population-based random-digit-dialing study investigating unwellness and chronic fatigue syndrome (CFS) in Georgia populations of three defined geographic areas (metropolitan, urban, and rural). Respondents were screened for symptoms of fatigue, sleep, cognition, and pain at household screening interviews, and a randomly selected sample completed detailed individual phone interviews. Based on the detailed phone interviews, we conducted one-day clinical evaluations of 292 detailed interview participants classified as unwell with a probable CFS (i.e. CFS-like; a functional somatic syndrome), 268 classified as other unwell, and 223 well (matched to (FS-like). Clinical evaluation included psychiatric classification by means of the Structured Clinical Interview for DSM (SCID). To derive prevalence estimates we used sample weighting to account for the complexity of the multistage sampling design. We used 2- and 3-way table analyses to examine socio-demographic and urbanicity specific associations and multiple logistic regression to calculate adjusted odds ratios.
\end{abstract}

Results: Anxiety and mood disorders were the most common psychiatric conditions. Nineteen percent of participants suffered a current anxiety disorder, 18\% a mood disorder and 10\% had two or more conditions. There was a significant linear trend in occurrence of anxiety or mood disorders from well to CFS-like. The most common anxiety disorders were post-traumatic stress disorder (PTSD) (6.6\%) and generalized anxiety disorder (GAD) (5.8\%). Logistic regression showed that lower education and female sex contributed significantly to risk for both PTSD and GAD. In addition, rural/urban residence and Hispanic ethnicity were associated with PTSD. We defined moderate to severe depression as Major Depressive Disorder or a Zung score $>60$ and logistic regression found lower education to be significantly associated but sex, age and urbanicity were not.

Conclusions: Overall occurrence of anxiety and mood disorders in Georgia mirrored national findings. However, PTSD and GAD occurred at twice the published national rates (3.6 and 2.7\%, respectively). State and local prevalence and associations with education, sex and urbanicity comprise important considerations for developing control programs. The increased prevalence of anxiety and mood disorders in people with a functional somatic syndrome (or CFS-like illness) is important for primary care providers, who should consider additional psychiatric screening or referral of individuals presenting with somatoform symptoms.

\footnotetext{
*Correspondence: dwe3@cdc.gov

${ }^{1}$ Public Health Surveillance and Informatics Program Office, Mail Stop E-33,

Centers for Disease Control and Prevention, 1600 Clifton Road NE, Atlanta,

GA, 30333, USA

${ }^{2}$ Chronic Viral Diseases Branch, Division of High-Consequence Pathogens and

Pathology, Mail Stop A-30, Centers for Disease Control and Prevention, 1600

Clifton Road NE, Atlanta, GA, 30333, USA

Full list of author information is available at the end of the article
}

\section{Biomed Central}

(c) 2013 Reeves et al.; licensee BioMed Central Ltd. This is an Open Access article distributed under the terms of the Creative Commons Attribution License (http://creativecommons.org/licenses/by/2.0), which permits unrestricted use, distribution, and reproduction in any medium, provided the original work is properly cited. 


\section{Background}

Mental illness is characterized by sustained abnormal alterations in thinking, mood or behavior associated with distress and impaired functioning [1]. Mental illness represents an important public health problem. According to the World Health Organization, mental illnesses account for more collective disability burden in developed countries than any other group of illnesses, including cancer and heart disease [2]. Published studies have reported that about one quarter of adults in the United States have a mental illness, and that about $46 \%$ will develop one during their lifetime [3,4]. Mental illness is estimated to cost the United States at least $\$ 300$ billion annually, including disability benefits of approximately $\$ 24$ billion [5], health care expenditures of $\$ 100$ billion [6] and lost earnings and wages of $\$ 193$ billion [7].

Disability and the burden imposed by mental illness also reflect associations with comorbid conditions. For example, depression is significantly associated with cardiovascular disease, diabetes, obesity, asthma, epilepsy, and cancer and with health risk behaviors such as alcohol abuse [8-11]. People with mental illness also have lower rates of access to and utilization of health care, poor chronic disease treatment compliance and a higher risk of adverse outcomes [12-15]. Finally, those with mental illness use tobacco more than the general population [16], and their rates for both intentional (e.g., homicide, suicide) and unintentional (e.g., motor vehicle) injuries are two to six times higher than in the general population $[17,18]$.

Various treatment and management interventions can reduce morbidity associated with specific mental illnesses and these interventions can be used by public health mental illness control programs. Public health control strategies for mental illness aim to reduce its prevalence, improve the clinical course, and reduce attendant impairment. Allocation of state and local resources for these programs must consider metropolitan, urban and rural population's differences in burden of illness. In addition, risk of various mental illnesses varies between women and men, by age and by socio-economic status. Providing mental illness services requires outreach, clinical training and staffing appropriate to each illness and setting. Finally, some categories of mental illness disproportionately affect disadvantaged groups (e.g., racial ethnic minorities, low education, below poverty level) and this must be considered as part of resource allocation. Public health officials need accurate population specific information concerning the occurrence of mental illness in order to design control strategies, implement them and evaluate their effectiveness.

Obtaining this information requires population surveys to estimate the prevalence of specific mental illnesses and associated risk factors. Mood and anxiety disorders frequently present with unexplained somatic symptoms
[19]. Such functional somatic syndromes commonly include complaints of fatigue, cognitive dysfunction, sleep disturbances and diffuse bodily pain [20-22]. One cost effective strategy for surveying mental illness uses an initial screening to identify those likely to have the illness followed by clinical evaluation of those who screen positive. This study compares detection of DSM-IV Axis I disorders [23] by means of the SCID in people screened as having a functional somatic syndrome and randomly selected people who did not meet screening criteria.

\section{Methods}

This study aimed to investigate the prevalence and correlates of major psychiatric disorders in metropolitan, urban, and rural Georgia populations

\section{Data source}

Data came from a study of unwellness and chronic fatigue syndrome (CFS) conducted between September 2004 and July 2005 in metropolitan, urban, and rural populations of Georgia [24]. The source study was approved by the Institutional Review Board of the Centers for Disease Control and Prevention (CDC) and affiliated institutions. All subjects gave written informed consent for participating in the study.

The source study included residents of three Georgia populations: 1) metropolitan Atlanta (Fulton and DeKalb Counties); 2) urban (Macon, Bibb County and the city of Warner Robins in adjacent Houston County); and 3) rural (10 counties surrounding Bibb - Houston (excluding Warner Robins), Baldwin, Bleckley, Crawford, Jones, Macon, Monroe, Peach, Twiggs, and Wilkinson). The study was carried out in three stages: 1) household screening telephone interview; 2) individual detailed telephone interview; and 3) clinical evaluation.

\section{Household screening telephone interview}

Sampling methodology and subjects have been described in detail [24]. In brief, a screening interview, with an adult household informant, (response rate 79\%) elicited demographic and health status of each household resident aged 18 to 59 and identified them as unwell or well. We defined unwell as the informant noting current fatigue, cognitive impairment, unrefreshing sleep, or musculoskeletal pain in a household resident during the last month. We defined household residents as well if the informant had not noticed any of these symptoms during the last month. A total of 12,089 adults were selected to participate in a detailed telephone interview: 3,851 residents identified as unwell with fatigue, 5,122 unwell but not fatigued, and 3,116 well.

\section{Individual detailed telephone interview}

We conducted detailed computer-assisted telephone interviews with 5,630 household residents aged 18 to 59 
identified by the informant as well or unwell. Seven people were later confirmed as age-ineligible for the detailed telephone interview. The detailed interview covered socio-demographic characteristics, current symptoms and their duration, and diagnosis of medical and psychiatric conditions considered exclusionary for clinic participation. Exclusionary conditions would confound associations of interest to the source study (of chronic fatigue syndrome) or could pose a risk or inconvenience for clinic participation. One thousand six hundred and nine $(28.6 \%)$ reported at least one such condition. Medical exclusions were the most common; morbid obesity (Body Mass Index $>=40 \mathrm{~kg} / \mathrm{m}^{2} ; 6 \%$ ), sleep apnea $(5 \%)$, or recent pregnancy $(5 \%)$. One hundred sixty-five (2.9\%) reported a psychiatric diagnosis; these included $72(1.3 \%)$ reporting a diagnosis of bipolar disorder, 49 (0.9\%) substance or alcohol abuse, 30 (0.5\%) schizophrenia, seven $(0.1 \%)$ anorexia or bulimia, and seven $(0.1 \%)$ other [25].

Based on the detailed interview data, we classified respondents who reported severe fatigue of at least six months duration and was accompanied by problems sleeping, cognitive difficulties and diffuse pain as CFS-like, which for the present analysis we considered a functional somatic syndrome (with high likelihood of a DSM-IV axis-I condition) $[19,20,26]$. We classified those who reported unwellness $\geq 6$ months that did not meet functional somatic syndrome criteria as other unwell. We classified remaining respondents as well.

\section{Clinical evaluation}

We invited all 469 individuals with a functional somatic syndrome (i.e., CFS-like)(and no exclusion) to participate in a one-day clinical evaluation, and 292 (62\%) completed. We invited 505 randomly selected other unwell people to participate, and 268 (53\%) completed. Finally, 223 randomly selected well individuals, frequency matched to the functional somatic syndrome participants by sex, race, age (+/- 3 years), and residential area, completed the one-day clinical evaluation.

During clinical evaluations a licensed nurse practitioner or physician assistant reviewed current medications, past medical history, and completed a review of systems. Participants then underwent a complete standardized physical examination by a physician and provided blood and urine specimens for routine clinical laboratory testing [24]. Licensed and specifically trained psychiatric interviewers administered the research version of the Structured Clinical Interview for DSM-IV (SCID) [27]. Psychologists on the CDC research team performed quality control checks of SCID interview results and monitored interviewers' technique on a regular basis. Raw SCID data was recorded as: 1 = Absent; $2=$ Subthreshold and $3=$ Threshold or Present. We identified the occurrence of \#3 (Threshold or Present) for both current episode (past month) and lifetime occurrence. Clinic participants also completed the SelfRating Depression Scale (SDS) [28], a 20-item questionnaire that quantifies the severity of current depression. We did not assess somatoform disorders identified by the SCID in this study because our objective was to use the telephone functional somatic syndrome screen to detect specific Axis-I disorders.

Analyses considered the following DSM-IV axis I diagnostic classes [23]: 1) mood disorders, which included major depressive disorder, dysthymia, depression not otherwise specified (NOS) and mood disorder due to a general medical condition (GMC); 2) anxiety disorders, comprised of panic disorder, generalized anxiety disorder (GAD), agoraphobia, specific phobia, social phobia, posttraumatic stress disorder (PTSD), obsessive-compulsive disorder (OCD), anxiety disorder due to general medical condition (GMC), substance-induced anxiety disorder , and anxiety NOS; 3) substance use disorders; and 4) adjustment disorder. Because not all people with severe depression meet DSM-IV criteria for major depressive disorder, we defined an additional category current moderate to severe depression as individuals diagnosed as major depressive disorder with the SCID or having a Zung Self Rating Depression score $>60$ [28].

\section{Sampling weights}

Prevalence estimates and statistical analyses used weighted data. The purpose of sampling weights is to account for the complexity of the multistage sampling design, nonresponse, and post-stratification. We generated two main sampling weights: one for the individuals who complete detailed interviews (termed interview sampling weights) and the other for the subset who complete clinical evaluations (termed clinical sampling weights). The details about these two sampling weights have been described elsewhere [24]. Sampling weights are assigned to each person based on the number of people they represent within the 2000 U.S. Census non-institutionalized civilian population. Sampling weights incorporated a further adjustment for clinical evaluation nonresponse and reflected the probability of selecting chronically unwell people for clinicalevaluation. Because "well" subjects were selected for clinical evaluation based on matching to those with a functional somatic syndrome, we estimated their sampling rates based on the response-rate adjusted sampling rates for the underlying sample of completed telephone interviews. Briefly, we estimated pseudo-weights, by three geographic strata, for the matched sub-sample based on observed demographic characteristics (age, sex, race (Black, White/Other) and the known sampling weights for similar individuals in the CFS-like sample. We weighted the 3 sampling strata in proportion to their size. 


\section{Statistical analyses}

This analysis only concerned the clinical sample of 765 subjects who had complete information from SCID interviews. We used the survey procedures of SAS Version 9.2 (SAS Institute Inc, Cary, NC) for all analyses to account for the complex sampling design (sampling weights) to calculate weighted estimates. We report weighted percentages of psychiatric disorder occurrence and their standard errors. We used 2- and 3-way table analyses to examine their association with geographic strata and other socio-demographic strata. We used logistic regression to estimate adjusted odds ratios (AORs) for categories of psychiatric disorders, controlling for socio-demographics. Significance level was 0.05 for two-sided tests.

\section{Results}

\section{Clinic participant characteristics}

Table 1 summarizes characteristics of all 782 clinic participants by unweighted frequency and weighted percentage.

\section{Overall occurrence of psychiatric conditions Specific psychiatric conditions}

Seven hundred sixty-five clinic participants had complete SCID data and we identified at least one current DSM-IV psychiatric disorder in $42 \%$ of them (Table 2). Anxiety and mood disorders represented the most commonly identified current psychiatric illnesses and occurred at similar rates (19.4 and 18.5 percent, respectively). The most common anxiety disorders were post-traumatic stress disorder (PTSD) (6.6\%) and generalized anxiety disorders (GAD) (5.8\%) followed by a specific phobia (4\%). Just over $1 \%$ had social phobia and obsessive compulsive disorder. Panic or agoraphobia and other anxiety disorders were rare. As expected, depression NOS and major depressive disorder dominated the mood disorders. More (45.8\%) participants had suffered a lifetime mood disorder than a lifetime anxiety disorder (31.7\%).

\section{Multiple conditions}

Among clinic participants with an anxiety or a mood disorder, most (19.6\%) had one psychiatric condition, 7.4\% had two conditions, $2.0 \%$ three, $1.1 \%$ four, and we identified five or more conditions in $0.3 \%$. Anxiety disorders were the most common; among participants with only one condition, as $27.4 \%$ had Anxiety NOS, $14.9 \%$ had PTSD, 14.3\% major depressive disorder, 12.1\% GAD and 11.4\% Specific Phobia. PTSD and GAD were most common among those with two disorders $(44.4 \%$ and $42.0 \%$, respectively. This general order also occurred for those with three, four, or $\geq$ five conditions (Table 3 ).

The remainder of this paper concerns current anxiety and mood disorders identified during the clinic evaluation. Both current anxiety and current mood disorders
Table 1 Clinic Participant Characteristics $(n=782)$

\begin{tabular}{|c|c|c|}
\hline & $n^{a}$ & Weighted \% \\
\hline \multicolumn{3}{|l|}{ Urbanicity } \\
\hline Metropolitan & 132 & 76.2 \\
\hline Urban & 267 & 11.1 \\
\hline Rural & 383 & 12.8 \\
\hline \multicolumn{3}{|l|}{ Sex } \\
\hline Female & 597 & 58.1 \\
\hline Male & 185 & 42.0 \\
\hline \multicolumn{3}{|l|}{ Race } \\
\hline White & 550 & 51.6 \\
\hline Black & 197 & 35.0 \\
\hline All Other & 35 & 13.5 \\
\hline \multicolumn{3}{|l|}{ Ethnicity } \\
\hline Hispanic & 20 & 2.3 \\
\hline Non-Hispanic & 762 & 97.7 \\
\hline \multicolumn{3}{|l|}{ Age } \\
\hline $18-29$ & 94 & 28.2 \\
\hline $30-39$ & 146 & 18.0 \\
\hline $40-49$ & 283 & 27.1 \\
\hline $50-59$ & 259 & 26.8 \\
\hline \multicolumn{3}{|l|}{ Education } \\
\hline$<$ High School & 205 & 14.3 \\
\hline High School +/-College & 318 & 31.8 \\
\hline$>$ College & 257 & 53.9 \\
\hline \multicolumn{3}{|l|}{ Income } \\
\hline$<\$ 20,000$ & 176 & 24.8 \\
\hline$\$ 20,000-\$ 40,000$ & 127 & 22.7 \\
\hline$>\$ 41,000$ & 450 & 52.6 \\
\hline \multicolumn{3}{|l|}{ Poverty } \\
\hline$<\$ 20,000$ & 176 & 24.8 \\
\hline$>\$ 20,000$ & 577 & 75.2 \\
\hline
\end{tabular}

${ }^{a}$ Not all 782 answered all questions concerning education, income or poverty status and 17 did not complete the SCID.

were significantly more common among functional somatic syndrome participants and there was a significant linear trend in occurrence increasing from Well to Unwell to functional somatic syndrome $(\mathrm{p}<.001)$ (Table 4).

\section{Anxiety and mood disorders Prevalence}

Overall, weighted prevalence of current anxiety disorders (19.4\%) and current mood disorders (18.5\%) were similar. Prevalence varied considerably by demographic features across the metropolitan, urban, and rural samples (Tables 5 and 6). 
Table 2 Weighted prevalence and $95 \%$ confidence intervals $(\mathrm{CI})$ of current and lifetime DSM-IV psychiatric conditions in selected Georgia counties

\begin{tabular}{|c|c|c|c|c|c|c|c|c|c|}
\hline \multicolumn{5}{|l|}{ Current DSM-IV Conditions } & \multicolumn{5}{|l|}{ Lifetime DSM-IV Conditions } \\
\hline & $\mathrm{n}$ & $\begin{array}{l}\text { Weighted } \\
\text { percent }\end{array}$ & Lower $\mathrm{Cl}$ & Upper Cl & & $\mathrm{n}$ & $\begin{array}{l}\text { Weighted } \\
\text { percent }\end{array}$ & Lower $\mathrm{Cl}$ & Upper Cl \\
\hline Anxiety Disorders & 287 & 19.4 & 12.7 & 26.2 & Anxiety Disorders & 374 & 31.7 & 19.8 & 43.5 \\
\hline Anxiety NOS & 77 & 7.1 & 3.2 & 11.0 & Anxiety NOS & 86 & 14.5 & 2.9 & 26.0 \\
\hline PTSD & 115 & 6.6 & 3.8 & 9.3 & PTSD & 216 & 9.9 & 6.3 & 13.5 \\
\hline GAD & 98 & 5.8 & 2.5 & 9.1 & & & & & \\
\hline Specific Phobia & 67 & 4.0 & 1.8 & 6.2 & Specific Phobia & 90 & 6.6 & 2.9 & 10.3 \\
\hline Social Phobia & 35 & 1.2 & 0.5 & 2.0 & Social Phobia & 51 & 2.5 & 1.0 & 4.0 \\
\hline OCD & 28 & 1.2 & 0.1 & 2.3 & OCD & 41 & 2.3 & 0.8 & 3.8 \\
\hline Panic & 26 & 1.0 & 0.3 & 1.8 & Panic & 66 & & & \\
\hline Agoraphobia & 12 & 0.8 & 0.00 & 1.6 & Agoraphobia & 21 & 1.5 & 0.3 & 2.6 \\
\hline Mood Disorders & 139 & 18.5 & 5.4 & 31.7 & Mood Disorders & 424 & 45.8 & 32.0 & 59.6 \\
\hline Depression NOS & 22 & 10.0 & 0.0 & 23.6 & Depression NOS & 72 & 21.8 & 6.0 & 37.6 \\
\hline Major Depressive Disorder & 101 & 7.3 & 3.2 & 11.5 & Major Depressive Disorder & 350 & 25.2 & 16.9 & 33.5 \\
\hline Dysthymia & 16 & 1.3 & 0.01 & 2.6 & & & & & \\
\hline Adjustment Disorders & 39 & 3.2 & 1.0 & 5.3 & & & & & \\
\hline
\end{tabular}

\section{Adjusted odds ratios}

To adjust for the main effects of socio-demographics, we calculated adjusted odds ratios for any current anxiety disorder and for any current mood disorder (Additional file 1: Table S1). Anxiety disorders were significantly more common among urban residents. Mood disorders were significantly less common among residents of the sampled rural counties and significantly more common among those who had attended high school or college.

\section{Anxiety disorders}

\section{Prevalence of specific anxiety disorders}

Anxiety disorders encompass a variety of conditions with different clinical manifestations and reflect different sociodemographic associations. PTSD (6.6\%) and GAD (5.8\%) were the most common anxiety disorders identified in the Georgia study, and their occurrence varied between metropolitan, urban, and rural populations according to socio-demographic characteristics (Additional file 1: Tables S2 and S3).

\section{Adjusted odds ratios of PTSD and GAD}

We included socio-demographics variables in multiple logistic regression models to calculate adjusted odds ratios for PTSD and for GAD. Both were significantly more common among women and those with less than a high school education. PTSD was also significantly more common among rural and urban residents and Hispanics (Additional file 1: Table S4).

\section{Moderate to severe depression}

\section{Prevalence of depression}

Major depressive disorder and depression NOS comprised the most common mood disorders detected by the SCID. To better characterize the population of depressed people in Georgia, we explored characteristics of current moderate to severe depression, which affected $7.39 \%$ of the Georgia population. Additional file 1: Table S5 presents weighted prevalence of current moderate to severe depression by demographic features in the metropolitan, urban, and rural populations. Women living in the urban strata were significantly more likely than men to be identified with moderate to severe depression and less than high school education was significantly associated in the rural population.

\section{Adjusted odds ratio of moderate to severe depression}

As with anxiety disorders, we included socio-demographic variables in multiple logistic regression models to calculate adjusted odds ratios for moderate to severe depression (major depressive disorder identified by the SCID or a Zung Self-Rating Depression Scale score > 60). Those with less than a high school education were significantly more likely to suffer current moderate to severe depression, Additional file 1: Table S6.

\section{Discussion}

Current anxiety (19.4\%) and mood disorders (18.5\%) were prevalent in residents of the selected Georgia counties. Overall, these findings agree with published U.S. national-level surveys. The 2001 to 2003 NCS-R, the 
Table 3 Occurrence of one, two, three, four and $\geq$ five DSM-IV conditions

\begin{tabular}{|c|c|c|c|c|c|c|c|c|c|}
\hline $\begin{array}{l}\text { One DSM-IV } \\
\text { Condition }\end{array}$ & $\begin{array}{l}\text { Weighted } \\
\%\end{array}$ & $\begin{array}{l}\text { Two DSM-IV } \\
\text { Conditions }\end{array}$ & $\begin{array}{l}\text { Weighted } \\
\%\end{array}$ & $\begin{array}{l}\text { Three DSM-IV } \\
\text { Conditions }\end{array}$ & $\begin{array}{l}\text { Weighted } \\
\%\end{array}$ & $\begin{array}{l}\text { Four DSM-IV } \\
\text { Conditions }\end{array}$ & $\begin{array}{l}\text { Weighted } \\
\%\end{array}$ & $\begin{array}{l}\geq \text { Four DSM-IV } \\
\text { Conditions }\end{array}$ & $\begin{array}{l}\text { Weighted } \\
\%\end{array}$ \\
\hline Anxiety NOS & 27.4 & PTSD & 44.4 & PTSD & 62.5 & MDD & 66.7 & PTSD & 92.9 \\
\hline PTSD & 14.9 & GAD & 42.0 & GAD & 59.2 & Specific Phobia & 61.9 & Specific Phobia & 92.3 \\
\hline MDD & 14.3 & MDD & 38.3 & MDD & 53.1 & PTSD & 61.9 & GAD & 64.3 \\
\hline GAD & 12.1 & Specific Phobia & 18.8 & Social Phobia & 22.9 & Social Phobia & 52.4 & Hypochondriasis & 64.3 \\
\hline Specific Phobia & 11.4 & Anxiety NOS & 18.5 & Specific Phobia & 20.4 & GAD & 33.3 & MDD & 57.1 \\
\hline Depression NOS & 5.8 & Depression NOS & 8.6 & Anxiety NOS & 18.4 & Panic & 28.6 & Panic & 50.0 \\
\hline Dysthymia & 4.7 & OCD & 7.4 & OCD & 16.7 & Anxiety NOS & 28.6 & Social Phobia & 50.0 \\
\hline OCD & 3.4 & Social Phobia & 6.2 & Panic & 14.3 & OCD & 25.0 & OCD & 21.4 \\
\hline Panic & 1.7 & Agoraphobia & 4.9 & Dysthymia & 8.5 & Hypochondriasis & 19.1 & Anxiety NOS & 21.4 \\
\hline Hypochondriasis & 1.7 & Panic & 3.7 & Agoraphobia & 8.2 & Dysthymia & 10.0 & Dysthymia & 14.3 \\
\hline Social Phobia & 1.7 & Mood - GMC & 2.5 & Depression NOS & 6.1 & Agoraphobia & 9.5 & Depression NOS & 14.3 \\
\hline Mood - GMC & 0.6 & Dysthymia & 1.3 & Mood - GMC & 6.1 & Depression NOS & 4.8 & Agoraphobia & 14.3 \\
\hline \multirow[t]{3}{*}{ Agoraphobia } & 0.6 & Mood-Substance & 1.2 & Hypochondriasis & 4.1 & & & & \\
\hline & & Anxiety-GMC & 1.2 & Anxiety-Substance & 2.0 & & & & \\
\hline & & Anxiety-Substance & 1.2 & & & & & & \\
\hline
\end{tabular}

Weighted \% - \% of those with 1, 2, 3, etc. conditions that have condition in that row.

NOS - Not Otherwise Specified.

PTSD - Post-Traumatic Stress Disorder.

MDD - Major Depressive Disorder.

GAD - Generalized Anxiety Disorder.

OCD - Obsessive-Compulsive Disorder.

Substance - accompanying a substance abuse disorder. 
Table 4 Association of current anxiety and mood disorders by telephone interview classification as functional somatic syndrome, other unwell and well

\begin{tabular}{|c|c|c|c|c|c|c|c|}
\hline \multirow[t]{2}{*}{ Current Condition } & \multicolumn{6}{|c|}{ Sample Category for Clinic Participation } & \multirow[b]{2}{*}{ Waldx2 Statistics } \\
\hline & Somatic Syndrome & Wtd \% & Other Unwell & Wtd \% & Well & Wtd \% & \\
\hline Any of Anxiety Disorders & & & & & & & 26.4 \\
\hline No & 136 & $45.8 \%$ & 170 & $82.0 \%$ & 180 & $88.8 \%$ & \\
\hline Yes & 156 & $54.2 \%$ & 98 & $18.0 \%$ & 42 & $11.2 \%$ & \\
\hline Any of Mood Disorders & & & & & & & 24.5 \\
\hline No & 195 & $61.9 \%$ & 229 & $79.4 \%$ & 213 & $95.9 \%$ & \\
\hline Yes & 97 & $38.1 \%$ & 39 & $20.6 \%$ & 9 & $4.1 \%$ & \\
\hline
\end{tabular}

$\mathrm{X} 2$ test for Sample category and any current Affective disorder $\mathrm{p}<0.001$.

$\mathrm{X} 2$ test for Sample category and any current Mood disorder $\mathrm{p}<0.001$.

Table 5 Weighted prevalence and 95\% confidence intervals $(\mathrm{CI})$ of any current anxiety disorder by demographic features in the Metropolitan, Urban and Rural populations

\begin{tabular}{|c|c|c|c|c|c|c|}
\hline & \multicolumn{2}{|l|}{ Metro } & \multicolumn{2}{|l|}{ Urban } & \multicolumn{2}{|l|}{ Rural } \\
\hline & $W t d \%$ & $95 \% \mathrm{Cl}$ & $W t d \%$ & $95 \% \mathrm{Cl}$ & $W t d \%$ & $95 \% \mathrm{Cl}$ \\
\hline Overall & 9.9 & $4.3-15.51$ & 28.7 & $19.2-38.1$ & 26.9 & $19.8-34.0$ \\
\hline \multicolumn{7}{|l|}{ Sex } \\
\hline Female & 19.8 & $10.4-29.1$ & 42.6 & $31.4-53.8$ & 43.4 & $33.7-53.1$ \\
\hline Male & 7.5 & $0-17.7$ & 26.5 & $9.9-43.1$ & 22.2 & $11.6-32.8$ \\
\hline \multicolumn{7}{|l|}{ Race } \\
\hline Other & 6.4 & $0-17.7$ & 34.0 & $0-78.2$ & 45.9 & 11.9-79.9 \\
\hline Black & 17.9 & $6.6-29.2$ & 35.0 & $20.5-49.4$ & 37.8 & $19.4-56.2$ \\
\hline White & 15.3 & $3.0-27.6$ & 36.2 & $22.9-49.4$ & 31.3 & 23.3-39.3 \\
\hline \multicolumn{7}{|l|}{ Ethnicity } \\
\hline Hispanic & 23.7 & $0-60.7$ & 35.1 & $0-85.9$ & 50.1 & 6.6-93.5 \\
\hline Non-Hispanic & 14.5 & $6.8-22.2$ & 35.7 & $25.8-45.5$ & 33.0 & $25.4-40.5$ \\
\hline \multicolumn{7}{|l|}{ Age } \\
\hline $18-29$ & 5.4 & $0-12.0$ & 40.3 & $16.4-64.1$ & 43.8 & $21.4-66.2$ \\
\hline $30-39$ & 10.9 & $0.8-20.9$ & 39.9 & $22.1-57.8$ & 49.6 & $31.8-67.4$ \\
\hline $40-49$ & 23.4 & $3.6-43.3$ & 25.8 & $14.6-36.9$ & 20.4 & 11.8-29.1 \\
\hline $50-59$ & 19.7 & $3.0-36.3$ & 39.0 & $16.2-61.8$ & 29.3 & $17.6-41.0$ \\
\hline \multicolumn{7}{|l|}{ Education } \\
\hline$<\mathrm{HS}$ & 38.6 & $2.6-74.7$ & 37.8 & 21.3-54.3 & 35.3 & $20.3-50.3$ \\
\hline HS-College & 11.6 & $0.6-22.7$ & 41.5 & $25.1-57.9$ & 35.4 & $24.1-46.7$ \\
\hline > College & 12.3 & $3.7-20.9$ & 24.5 & $11.2-37.7$ & 25.8 & $15.1-36.5$ \\
\hline \multicolumn{7}{|l|}{ Income } \\
\hline$<\$ 20,000$ & 19.4 & $1.3-37.6$ & 38.5 & $21.5-55.5$ & 28.0 & $12.4-43.6$ \\
\hline$\$ 20-\$ 40 \mathrm{~K}$ & 8.7 & $0-24.4$ & 55.9 & $35.8-76.0$ & 49.2 & $27.2-71.2$ \\
\hline$>\$ 41,000$ & 14.3 & $4.7-23.8$ & 26.1 & 12.6-39.6 & 29.0 & $20.4-37.6$ \\
\hline \multicolumn{7}{|l|}{ Poverty } \\
\hline$>\$ 20,000$ & 12.5 & $4.3-20.8$ & 35.0 & $23.4-46.7$ & 33.4 & $24.8-42.0$ \\
\hline$<\$ 20,000$ & 19.4 & $1.3-37.6$ & 38.5 & 21.5-55.5 & 28.0 & $12.4-43.6$ \\
\hline
\end{tabular}


Table 6 Weighted prevalence and $95 \%$ confidence intervals ( $\mathrm{Cl}$ ) of any mood disorder by demographic features in the Metropolitan, Urban and Rural populations

\begin{tabular}{|c|c|c|c|c|c|c|}
\hline & Metro & & Urban & & Rural & \\
\hline & $W t d \%$ & $95 \% \mathrm{Cl}$ & $W t d \%$ & $95 \% \mathrm{Cl}$ & Wtd \% & $95 \% \mathrm{Cl}$ \\
\hline Overall & 20.6 & $3.6-37.7$ & 14.3 & 8.6-19.7 & 9.5 & $5.5-13.6$ \\
\hline \multicolumn{7}{|l|}{ Sex } \\
\hline Female & 13.6 & $5.7-21.6$ & 18.3 & $10.5-26.0$ & 13.3 & $6.7-19.8$ \\
\hline Male & 30.8 & $0-68.4$ & 9.0 & $1.2-16.9$ & 5.4 & $1.3-9.5$ \\
\hline \multicolumn{7}{|l|}{ Race } \\
\hline Other & 63.6 & 14.9-100.0 & 0 & $0-0$ & 7.8 & $0-16.9$ \\
\hline Black & 10.5 & $2.8-18.3$ & 16.7 & $6.8-26.7$ & 16.8 & $4.6-29.0$ \\
\hline White & 13.2 & $1.9-24.5$ & 13.7 & $6.4-21.0$ & 7.0 & $3.4-10.7$ \\
\hline \multicolumn{7}{|l|}{ Ethnicity } \\
\hline Hispanic & 39.7 & $0-90.1$ & 0.0 & $0-0$ & 2.2 & $0-6.9$ \\
\hline Non-Hispanic & 20.2 & $2.74-37.6$ & 14.7 & $8.8-20.5$ & 9.6 & $5.5-13.7$ \\
\hline \multicolumn{7}{|l|}{ Age } \\
\hline $18-29$ & 32.4 & $0-77.9$ & 13.5 & $0-27.4$ & 13.4 & $0-28.1$ \\
\hline $30-39$ & 12.6 & $0.01-25.2$ & 17.7 & 4.7-30.7 & 17.1 & $5.5-28.7$ \\
\hline $40-49$ & 23.6 & $3.5-43.7$ & 14.4 & $5.4-23.3$ & 4.0 & $1.5-6.6$ \\
\hline $50-59$ & 9.0 & $0.6-17.5$ & 11.6 & $1.6-21.6$ & 7.7 & $2.2-13.3$ \\
\hline \multicolumn{7}{|l|}{ Education } \\
\hline$<\mathrm{HS}$ & 19.7 & $0-49.8$ & 25.8 & $11.7-39.9$ & 11.6 & 3.9-19.3 \\
\hline HS-College & 44.8 & $3.5-86.1$ & 10.7 & $3.5-18.0$ & 10.0 & $3.6-16.4$ \\
\hline$>$ College & 10.3 & $2.6-17.9$ & 8.8 & $0-18.1$ & 5.7 & $0.1-11.3$ \\
\hline \multicolumn{7}{|l|}{ Income } \\
\hline$<\$ 20,000$ & 13.7 & $0-29.2$ & 27.9 & $12.1-43.8$ & 7.7 & $2.2-13.3$ \\
\hline$\$ 20-\$ 40 \mathrm{~K}$ & 54.9 & $11.7-98.2$ & 18.2 & $4.5-32.1$ & 16.9 & $4.2-29.5$ \\
\hline$>\$ 41,000$ & 9.1 & 2.4-15.9 & 6.7 & $1.5-11.8$ & 7.5 & $2.1-12.9$ \\
\hline \multicolumn{7}{|l|}{ Poverty } \\
\hline$<\$ 20,000$ & 13.7 & $0-29.2$ & 27.9 & $12.1-43.8$ & 7.7 & $2.2-13.3$ \\
\hline$>\$ 20,000$ & 23.6 & $1.1-46.1$ & 10.1 & $4.5-15.7$ & 9.6 & $4.6-14.6$ \\
\hline
\end{tabular}

most comprehensive national study, used the Composite International Diagnostic Interview (CIDI) [29-31] and reported $18.2 \%$ of U.S. adults had an anxiety disorder and $19.5 \%$ a mood disorder [32]. Occurrence of major depressive disorder in the selected Georgia counties was similar to NCS-R national estimates $(7.3 \%$ and $6.7 \%$, respectively) [32]. Most of those with a mental illness detected in our study (19\%) suffered only one, 7.4\% had two psychiatric conditions, $2 \%$ had three, and $1.4 \%$ four or more, which also mirrors NCS-R reported findings; $14.4 \%$ of people with a psychiatric disorder had only one, $5.9 \%$ had two, and 5.9\% three or more [32]. However both order and magnitude of specific anxiety disorder prevalence in our Georgia population sample differed markedly from 2001 to 2003 NCS-R national estimates. In Georgia, PTSD (6.6\%) and GAD (5.8\%) were the most common anxiety disorders followed by specific phobia (4.0\%) and social phobia (1.2\%); while, specific phobia (8.7\%), social phobia (6.8\%), PTSD (3.6\%) and GAD were the most common anxiety disorders reported from NCS-R (2.7\%) [32]. This difference in our findings from Georgia and NCS-R highlights that national surveys may not reflect category-specific occurrence of mental illness in individual states. For example, a recent report indicates depression and psychological distress are more common in the southeastern states than the nation as a whole [33]. However, it is also possible that this variation in prevalence estimates may be due to methodological differences between our study and the NCS-R, such as using a state-specific sample rather than a national sample and the SCID rather than CIDI as a diagnostic tool.

As we hypothesized, both current anxiety and current mood disorders were significantly more common among 
people identified by telephone interview as unwell (functional somatic syndrome or other unwell). Fifty three percent of functional somatic syndrome participants had a current anxiety disorder and 32\% a current mood disorder; among those classified as well only $18.9 \%$ had an anxiety disorder and $3.7 \%$ a mood disorder. The increased prevalence of anxiety and mood disorders in people with a functional somatic syndrome is important for primary care providers, who should consider additional psychiatric screening or referral of individuals presenting with somatoform symptoms. This association also has implications for psychiatric nosology and development of DSM-V $[19,22]$. As noted in a recent review by Lieb et al. [34], there is a remarkable lack of data evaluating occurrence of anxiety and mood disorders among people with a functional somatic syndrome. Research surveys for mental illness should consider screening for functional somatic syndromes to help resolve questions of nosology and surveillance systems intended for public health use should also measure functional somatic syndromes as part of screening for anxiety and mood disorders.

In our Georgia study sample, anxiety and mood disorders varied considerably according to socio-demographic factors among metropolitan, urban and rural samples. Our study found no significant difference among the three geographic areas in the prevalence of having any current mood disorder, whereas previous U.S. studies have reported a slight but significantly higher prevalence of depression in rural areas than metropolitan area $[35,36]$. Future work should investigate whether there may be unique aspects of mental health treatment or access to treatment in urban and rural Georgia that are associated with this non-significant effect. On the contrary, for current anxiety disorders, our study results showed that there was a significantly higher prevalence in urban and rural areas than that in the metropolitan area. Logistic regression modeling of PTSD and GAD (the most common anxiety disorders) found both significantly associated with female sex and education less than high school. PTSD was also significantly associated with rural and urban residence but residence and ethnicity were not associated with GAD. This finding might indicate more limited availability of and referral to treatment opportunities for those living in rural and urban locations who have encountered traumatic events. A recent study has shown that veterans with PTSD had significantly fewer treatment visits when living in rural areas than those living in bigger cities [37]. Another study observed that referrals after a natural disaster were markedly higher in large cities (Atlanta among them) compared to urban locations [38]. Logistic regression modeling of moderate to severe depression showed less than high school education as the most significant factor and no significant association with sex or urbanicity. These findings add to the evidence base that should be considered when designing mental illness control programs. For both anxiety and mood disorders, messaging and education must consider educational attainment. In Georgia, programs for PTSD and GAD should also consider outreach to gynecologists, who often serve as women's primary care providers. Finally, in Georgia the association of urban and rural residence with PTSD should be considered when developing clinical services and messaging for these segments of the population.

To our knowledge, CDC's Behavioral Risk Factor Surveillance System (BRFSS) comprises the only population survey of depression in Georgia against which to compare our findings. In 2006 and 2008 BRFSS conducted random digit dial telephone interviews with adults and estimated that $9.0 \%$ were depressed during the last 2 weeks, as reflected by a PHQ-8 score $>10$ [33], which is similar to our finding that $9.8 \%$ of the selected Georgia counties' study population suffered moderate to severe depression during the last month. BRFSS has also estimated that $3.4 \%$ of Georgia adults had major depression, which is quite different from our estimated $7.3 \%$ prevalence of major depressive disorder in the selected Georgia counties. This most likely occurred because the PHQ-8 screens for depression in the last two weeks and does not identify DSM-IV major depressive disorder as stringently measured by means of the SCID (at least two weeks during the last month). BRFSS has not published results concerning factors associated with depression in Georgia against which to compare our present findings (e.g., associations with age, sex, race/ethnicity, metropolitan/urban/rural residence, education, or household income). Unfortunately, BRFSS does not measure other categories of mental illnesses, such as anxiety disorders, which our survey found to be as common and disabling as depression and which also reflected different associations with socio-demographic variables than did depression.

\section{Strengths and limitations}

One of the strengths of this study is the use of a large sample identified from metropolitan, urban, and rural Georgia populations through phone interviews and clinical evaluations. In addition, this study used the SCID as a diagnostic tool for psychiatric disorders evaluated in the paper.

There are two major limitations of our study. Most importantly, we used Fulton and DeKalb counties to represent metropolitan Georgia, Macon and Warner Robins represented urban Georgia, and counties surrounding them represented rural Georgia. We chose this approach for logistical reasons. Fulton and DeKalb counties are the heart of Atlanta and meet US Department of Agriculture metropolitan population criteria [39]. However, 14 additional counties comprise the Atlanta metropolitan area 
and were not sampled. Macon (Bibb County) and Warner Robins are considered urban [39] but are not necessarily similar to other Georgia urban populations (e.g., Savannah, Athens and Rome). Due to cross-sectional data, we could not infer causal relationships between the psychiatric diagnoses and socio-demographic variables. The study also suffered from the non-coverage for institutionalized and non-English speaking populations. Finally, although our rural study counties fulfill USDA criteria for rural [39], their populations may differ from those of rural counties in the north Georgia mountains or southern coastal plain. Further analyses of the publically available BRFSS database may provide information concerning the effects of such possible differences on occurrence of depression.

Second, selection for clinical evaluation was not random, but was based on wellness status detected by the telephone interview. The source study was enriched in fatiguing illness and potentially identified high prevalence of undiagnosed psychiatric conditions. We attempted to adjust for clinic selection bias by weighting, which has attendant methodological limitations. Finally, reflecting sample size, some standard errors are large.

\section{Conclusions}

This report was limited to describing occurrence of anxiety and mood disorders in different Georgia populations. Additional analyses will evaluate other factors known to be associated with these disorders and that the survey also measured (e.g., obesity, metabolic syndrome, diabetes, childhood abuse, access to and utilization of health care, and economic impact). We evaluated the 2004-2005 survey cohort again between 2007 and 2009; analyses will explore clinical course of these anxiety and mood disorders, their incidence, and their associations with socio-demographic variables and comorbid conditions. Effective public health initiatives to control mental illness could be better focused based on this knowledge. Research surveys such as ours are not optimal for routine public health surveillance. However, BRFSS exemplifies successful state/local surveillance that collects uniform, state-specific data concerning preventive health practices and risk behaviors associated with chronic disease, injuries and infectious diseases in the adult population. States use BRFSS data to identify emerging health problems, to establish and track health objectives, and to develop and evaluate public health policies and programs. For many states, BRFSS is the only source of timely, accurate state-based data on health-related behaviors. BRFSS surveillance data for Georgia and other states is publically available [40] and future analyses will explore similarities between our mental illness and associated risk factors identified in our research study and BRFSS data related to depression and psychological distress. Based on this, we will plan mental health specific surveillance appropriate for use by states.

Our findings may provide public health officials with accurate population specific information concerning the occurrence of mental illness. This will enable them to design control strategies, implement these strategies, and evaluate their effectiveness, especially in disproportionately affected disadvantaged groups (e.g., racial ethnic minorities, low education, below poverty level).

\section{Additional file}

\section{Additional file 1: The supplementary material includes the supplement Tables S1-S6 for the adjusted odds ratios for socio- demographic correlates of major psychiatric disorders in metropolitan, urban, and rural Georgia population.}

\section{Abbreviations}

SCID: Structured Clinical Interview for DSM; PTSD: Post-Traumatic Stress Disorder; GAD: Generalized Anxiety Disorder; CDC: Centers for Disease Control and Prevention; GMC: General Medical Condition; OCD: Obsessive Compulsive Disorder; NOS: Not Otherwise Specified; AOR: Adjusted Odds Ratios; BRFSS: Behavioral Risk Factor Surveillance System.

\section{Competing interests}

The authors declare that they have no competing interests.

\section{Authors' contributions}

WCR, JML and UMN were involved in the conception, design and conduct of the study. WCR JML and UMN were involved in the analysis and interpretation of the data. WCR, JML and UMN wrote the manuscript. All authors have read and approved the final manuscript.

\section{Acknowledgements}

This study was fully funded by the US Centers for Disease Control and Prevention (CDC). The authors are indebted to Abt Associates staff responsible for field work and in particular to Ms. Rebecca Devlin for study management. We especially appreciate the time Dr. Anil T. Mangla (Acting State Epidemiologist, Georgia Department of Community Health) took to review and discuss this paper.

Drs. Reeves and Lin are fully supported by the Centers for Disease Control and Prevention. The study was fully funded by the Centers for Disease Control and Prevention. Dr. Nater acknowledges funding by the VolksWagen Foundation and the Swiss National Science Foundation.

\section{Author details}

${ }^{1}$ Public Health Surveillance and Informatics Program Office, Mail Stop E-33, Centers for Disease Control and Prevention, 1600 Clifton Road NE, Atlanta, GA, 30333, USA. ²Chronic Viral Diseases Branch, Division of HighConsequence Pathogens and Pathology, Mail Stop A-30, Centers for Disease Control and Prevention, 1600 Clifton Road NE, Atlanta, GA, 30333, USA.

${ }^{3}$ Department of Psychology, University of Marburg, Marburg, Germany.

Received: 18 June 2012 Accepted: 22 April 2013

Published: 30 April 2013

\section{References}

1. U.S. Department of Health and Human Services: Mental health: a report of the Surgeon General. Rockville, MD: U.S. Department of Health and Human Services, Substance Abuse and Mental Health Services Administration, Center for Mental Health Services, National Institutes of Health, National Institute of Mental Health; 1999. http://www.surgeongeneral.gov/library/ mentalhealth/home.html

2. World Health Organization: Promoting mental health: concepts, emerging evidence, practice (summany report). Geneva (CH): World Health Organization; 2004. 
3. Kessler RC, Chiu WT, Demler O, Walters EE: Prevalence, severity, and comorbidity of twelve-month DSM-IV disorders in the National Comorbidity survey replication (NCS-R). Arch Gen Psychiatry 2005, 62:617-627.

4. Kessler RC, Wang PS: The descriptive epidemiology of commonly occurring mental disorders in the United States. Ann Rev Public Health. 2008, 29:115-129.

5. Insel TR: Assessing the economic costs of serious mental illness. Am J Psych. 2008, 165:663-665.

6. Mark TL, Levit KR, Buck JA, Coffey RM, Vandivort-Warren R: Mental health treatment expenditure trends, 1986-2003. Psychiatr Serv 2007, 58:1041-1048.

7. Kessler RC, Heeringa S, Lakoma MD, Petukhova M, Rupp AE, Schoenbaum M, Want PS, Zaslavsky AM: Individual and societal effects of mental disorders on earnings in the United States: results from the National Comorbidity Survey Replication. Am J Psychiatry 2008, 165:703-711.

8. Chapman DP, Perry GS, Strine TW: The vital link between chronic disease and depressive disorders. Prev Chronic Dis 2005, 2(1):A14.

9. Evans DL, Charney DS, Lewis L, Golden RN, Gorman JM, Krishnan KR, et al: Mood disorders in the medically ill: scientific review and recommendations. Biol Psychiatry 2005, 58(3):175-89.

10. El-Gabalawy R, Katz LY, Sareen J: Comorbidity and associated severity of borderline personality disorder and physical health conditions in a nationally representative sample. Psychosomatic Med. doi:10.1097/ PSY.0b013e318e10c7b.

11. Lichtman JH, Bigger JT Jr, Blumenthal JA, Frasure-Smith N, Kaufmann PG, Lespérance $F$, et al: Depression and coronary heart disease: recommendations for screening, referral, and treatment: a science advisory from the American Heart Association Prevention Committee of the Council on Cardiovascular Nursing, Council on Clinical Cardiology, Council on Epidemiology and Prevention, and Interdisciplinary Council on Quality of Care and Outcomes Research: endorsed by the American Psychiatric Association. Circulation 2008, 118(17):1768-75.

12. Pincus H, Watkins $K$, Houtsinger J, Keyser D: Applying the Institute of Medicine quality chasm framework to improving health care for mental and substance use conditions. The Psychiatric Clin North Am. 2008, 31:43-56

13. Broadbent E, Kydd R, Sanders D, Vanderpyl J: Unmet needs and treatment seeking in high users of mental health services: role of illness perceptions. Aust N Z J Psychiatry 2008, 42:147-153.

14. Levinson D, Karger CJ, Haklai Z: Chronic physical conditions and use of health services among persons with mental disorders: results from the Israel National Health Survey. Gen Hosp Psychiatry 2008, 30:226-232.

15. Shen C, Sambamoorthi U, Rust G: Co-occurring mental illness and health care utilization and expenditures in adults with obesity and chronic physical illness. Dis Manag 2008, 11:153-160.

16. Lasser K, Boyd JW, Wooljandler S, Himmelstein DU, McCormick D, Dor DH: Smoking and mental illness: a population-based prevalence study. JAMA 2000, 284(20):2606-10

17. Hiroeh U, Appleby L, Mortensen PB, Dunn G: Death by homicide, suicide and other unnatural causes in people with mental illness: a populationbased study. Lancet 2001, 358(9299):2110-2.

18. Wan JJ, Morabito DJ, Khaw J, Knudson MM, Dicker RA: Mental illness as an independent risk factor for unintentional injury and injury recidivism. J Trauma 2006, 61(6):1299-304.

19. Dimsdale JE, Patel V, Xin Y, Kleinman A: Somatic presentations - a challenge for DSM-V. Psychosom Med 2007, 69:829.

20. Wessely S, Nimnuan C, Sharpe M: Functional somatic syndromes: one or many? Lancet 1999, 354:936-939.

21. Kato K, Sullivan PF, Evengard B, Pedersen NL: A population-based twin study of functional somatic syndromes. Psychol Med 2009, 39:497-505.

22. Kanaan RAA, Lepine JP, Wessely SC: The association or otherwise of the functional somatic syndromes. Psychosom Med 2007, 69:855-859.

23. American Psychiatric Association: Diagnostic and Statistical Manual for Mental Disorders. 4th edition. Washington, DC: APA; 2000.

24. Lin JMS, Resch SC, Brimmer DJ, et al: The economic impact of chronic fatigue syndrome in Georgia: direct and indirect costs. Cost Effectiveness and Resource Allocation. 2011, 9:1

25. Jones JF, Lin JMS, Maloney EM, Boneva RS, Nater UM, Unger ER, Reeves WC: An evaluation of exclusionary medical/psychiatric conditions in the definition of chronic fatigue syndrome. BMC Med 2009, 7:57.

26. Regier DA: Somatic presentations of mental disorders: refining the research agenda for DSM-V. Psychosom Med 2007, 69:827-828.
27. First MB, Spitzer RL, Gibbon M, Williams JBW: Structured clinical interview for DSM-IV-TR Axis I disorders, research version. New York: Biometrics Research, New York State Psychiatric Institute; 2002.

28. Zung WW: From art to science. The diagnosis and treatment of depression. Arch Gen Psychiatry 1973, 29:328-337.

29. Kessler RC, Berglund P, Demler O, Jin R, Merikangas KR, Walters EE: Lifetime prevalence and age-of-onset distributions of DSM-IV disorders in the National Comorbidity Survey Replication. Arch Gen Psychiatry 2005, 62:593-602

30. Kessler RC, Ustun TB: The World Mental Health (WMH) Survey Initiative Version of the World Health Organization (WHO) Composite International Diagnostic Interview (CIDI). Int Journal Methods in Psychiatric Research. 2004, 13:93-121.

31. Kessler RC, Berglund P, Chiu WT, Demler O, Heeringa S, Hiripi E, et al: The US National Comorbidity Survey Replication (NCS-R): Design and field Procedures. Int J Methods in Psychiatric Res. 2004, 13:16-92.

32. Kessler RC, Chiu WT, Colpe L, Demler O, Merikangas KR, Walters EE, Wang PS: Chapter 15. The Prevalence and Correlates of Serious Mental IIIness (SMI) in the National Comorbidity Survey Replication (NCS-R). In Mental Health, United States, 2004. Center for Mental Health Services. Mental Health, United States, 2004. Manderscheid, R.W., and Berry, J.T., eds. DHHS Pub no. (SMA)-06-4195. Substance Abuse and Mental Health Services Administration: Rockville, MD; 2006.

33. Centers for Disease Control and Prevention: Current depression among adults - United States, 2006 and 2008. Morb Mortal Wkly Rep 2010, 59(38): 1229-1235. http://www.cdc.gov/mmwr/preview/mmwrhtml/mm5938a2.htm.

34. Lieb R, Meinlschmidt G, Araya R: Epidemiology of the association between somatoform disorders and anxiety and depressive disorders: an update. Psychosom Med 2007, 69:860-863.

35. Probst JC, Laditka SB, Moore CG, Harun N, Powell MP, Baxler EG: Ruralurban differences in depression prevalence: implications for family medicine. Fam Med 2006, 38:653-60.

36. Strine TW, Dhingra SS, Kroenke K, Qayad M, Ribble JL, Okoro CA, Balluz LS, Dube SR, Lando J, Mokdad AH: Metropolitan and micropolitan statistical area estimates of depression and anxiety using the Patient Health Questionnaire-8 in the 2006 Behavioral Risk Factor Surveillance System. Int J Public Health 2009, 54(2):117-24.

37. Brooks E, Novins DK, Thomas D, Jiang L, Nagamoto HT, Dailey N, Bair B, Shore JH: Personal characteristics affecting veterans' use of services for posttraumatic stress disorder. Psychiatr Serv 2012, 63(9):862-7.

38. Rosen CS, Matthieu MM, Norris FH: Factors predicting crisis counselor referrals to other crisis counseling, disaster relief, and psychological services: a cross-site analysis of post-Katrina programs. Adm Policy Ment Health 2009, 36(3):186-94.

39. U.S. Department of Agriculture: Rural-urban Continuum Codes. http:/www. ers.usda.gov.Data/RuralUrban/Continuum/Codes/

40. Centers for Disease Control and Prevention: Behavioral Risk Factor Surveillance System. Survey Data and Downloads. http://www/cdc/gov/brfss/index.htm.

doi:10.1186/1471-2458-13-414

Cite this article as: Reeves et al: Mental illness in metropolitan, urban and rural Georgia populations. BMC Public Health 2013 13:414.

\section{Submit your next manuscript to BioMed Central and take full advantage of:}

- Convenient online submission

- Thorough peer review

- No space constraints or color figure charges

- Immediate publication on acceptance

- Inclusion in PubMed, CAS, Scopus and Google Scholar

- Research which is freely available for redistribution 